\title{
A etnoecologia: uma ciência pós-normal que estuda as sabedorias tradicionais
}

\section{Ethnoecology: A Post-Normal Science Studying the Traditional Knowledge and Wisdom}

\author{
Victor Manuel TOLEDO* \\ Narciso BARRERA-BASSOLS**
}

\begin{abstract}
RESUMO
O artigo revela uma maneira de valorizar os conhecimentos milenares sobre a natureza dos povos indígenas e rurais do planeta. Esta valorização se denomina Etnoecologia, nova disciplina híbrida, transdisciplinar e pós-normal. Distinguem-se as duas tradições intelectuais que elaboraram uma compreensão sobre a natureza: a ocidental, forjadora da ciência moderna e a que aglutina diversas formas de compreensão sobre o mundo natural, denominada a experiência tradicional. Assim, é possível distinguir duas ecologias e não só aquela que organiza a ciência moderna e que tornou invisível as ecologias das 7.000 culturas indígenas que resistem à expansão do mundo industrial e que sustentam os ecossistemas planetários. Torná-las visíveis requer um pensamento crítico que oferece o olhar etnoecológico. Discutem-se os traços principais do conhecimento tradicional. Quem são os sujeitos sociais que o animam. Como se transmite e pratica. Quais são seus resultados simbólicos e práticos. O que nos ensina e como a Etnoecologia revela sua complexidade mediante o estudo do complexo k-c-p, que sintetiza a teorização, representação e produção do mundo sócionatural dos outros. Este jogo duplo que potencia o diálogo de saberes permite ao etnoecologista analisar o mundo dos outros e oferece seu próprio escrutínio sobre esses mundos. Isso permite reinventar possíveis futuros. Finalmente, discute-se por que a Etnoecologia tem a singular tarefa de decifrar a "memória de nossa espécie", isto é, a memória biocultural, reivindicando e revalorizando a quem a mantêm em vez de aprofundar a crítica sobre o mundo moderno e sua racionalidade intelectual.
\end{abstract}

Palavras-chave: povos indígenas; conhecimento local; sabedorias tradicionais; investigação participativa.

\section{RESUMEN}

El artículo revela una manera de valorar los conocimientos milenarios sobre la naturaleza de los pueblos indígenas y rurales del planeta. A esta valoración se le denomina Etnoecología, novel disciplina híbrida, transdisciplinaria y post-normal. Se distinguen las dos tradiciones intelectuales que han elaborado una comprensión sobre la naturaleza: la occidental forjadora de la ciencia moderna y la que aglutina diversas formas de comprensión sobre el mundo natural, denominada la experiencia tradicional. Así, es posible

\footnotetext{
" Doctor en Ciencias (Ecología) por la Universidad Nacional Autónoma de México (UNAM), e investigador del Centro de Investigaciones en Ecosistemas de la UNAM.

"* Doctor en Ciencias por la Universidad de Ghent, Bélgica e investigador del Centro de Investigaciones en Geografía Ambiental de la UNAM.
} 
distinguir dos ecologías y no solo aquella que organiza la ciencia moderna y que ha invisibilizado las ecologías de las 7,000 culturas indígenas que resisten la expansión del mundo industrial y quienes sostienen los ecosistemas planetarios. Hacerlas visibles requiere de un pensamiento critico que ofrece la mirada etnoecológica. Se discuten los principales rasgos del conocimiento tradicional. Quiénes son los sujetos sociales que lo animan. Cómo se transmite y practica. Cuáles son sus resultados simbólicos y prácticos. Qué nos enseña y cómo la Etnoecología revela su complejidad mediante el estudio del complejo k-c-p, que sintetiza la teorización, representación y producción del mundo socionatural de los otros. Este doble juego que potencia el diálogo de saberes, permite al etnoecológo analizar el mundo de los otros y ofrece su propio escrutinio sobre esos mundos. Ello permite reinventar posibles futuros. Finalmente, se discute por qué la Etnoecología tiene la singular tarea de descifrar la "memoria de nuestra especie", esto es, la memoria biocultural, reivindicando y revalorizando a quienes la mantienen a la vez de profundizar la critica sobre el mundo moderno y su racionalidad intelectual.

Palabras clave: pueblos indígenas; conocimiento local; sabidurías tradicionales; investigación participativa.

\begin{abstract}
The article reveals a way of evaluating millenary knowledge of indigenous and rural peoples' views about nature. This type of inquiry is denominated ethnoecology, a novel, hybrid, transdisciplinary, and post-normal discipline. Two intellectual traditions regarding how nature is perceived are defined: the Western thought based on Modern science, and another - here denominated traditional experience - that encompasses diverse ways of conceiving the natural world. Thus, two types of ecology emerge, and not just the one based on Modern science, which eclipsed the ecological myriads of some 7,000 indigenous cultures that today resist the expansion of the industrialized world while sustaining ecosystems at planetary level. Making them visible requires the kind of critical thinking offered by an ethnoecological approach. This type of evaluation defines the characteristics of traditional knowledge, what kinds of social actors support it, how it is transmitted and practiced both on symbolic and practical levels. We show what ethnoecology has to teach and how nature's complexity is revealed through the study of the k-c-p complex, which synthesizes the theorization, representation, and production of the socio-natural worlds of the "others". This double role permits a dialogue between types of knowledge, allowing the ethnoecologist to analyze the worlds of "others", offering an individual interpretation of them. It also leads to the reinvention of possible futures. Finally, the article discusses how it is that ethnoecology has the singular task of deciphering the "memory of our species", that is the bio-cultural memory, recognizing and re-evaluating those peoples who maintain it while bringing new depth to criticism of the Modern world and its intellectual rationality.
\end{abstract}

Key-words: indigenous peoples; local knowledge; traditional wisdom; participatory research.

\section{Introdução}

A nós, os pesquisadores treinados nos recintos acadêmicos da ciência moderna, ensinaram a entender as técnicas, a inventariar as espécies utilizadas, e a descobrir os sistemas de produção, energia e abastecimento por meio dos quais os grupos humanos se apropriam da natureza. Poucas vezes nos ensinaram a reconhecer a existência de uma experiência, de certa sabedoria, nas mentes de milhões de homens e mulheres que dia após dia trabalham a natureza precisamente mediante essas técnicas, essas espécies e esses sistemas. Hoje, no alvorecer de um novo século, esses homens e mulheres formam ainda a maior parte da população dedicada a apropriar-se dos ecossistemas do planeta. E é justamente esse esquecimento da investigação científica o que fez com que a civilização industrial fracassasse em suas tentativas de realizar um manejo adequado da natureza.

A colocação anterior remete ao reconhecimento da existência de duas tradições intelectuais, cada uma com origens, traços e capacidades diferentes. Se o Ocidente gestou formas de compreensão e de articulação de e com 
a natureza, cuja origem remonta apenas à do início da Revolução Industrial, na maior parte do mundo existem, de maneira paralela, outras modalidades de relação com a natureza que, originadas a vários milhares de anos, encontram-se ainda presentes no mundo contemporâneo (TOLEDO; BARRERA-BASSOLS, 2008). Essas modalidades de articulação com a natureza de estirpe pré-moderna, ou, se preferir, pré-industrial, encontram-se embebidas nas cerca de 7.000 culturas não-ocidentais (os povos indígenas) que ainda existem no início do novo milênio nas áreas rurais daquelas nações que, por resistência ou por marginalidade, conseguiram resistir ou evitar a expansão cultural e tecnológica do mundo industrial (TOLEDO, 2001; MAFFI, 2001).

Esses enclaves ainda mantêm rasgos de civilização tradicionais ou não modernos em sua contínua interação com a natureza. Essa outra tradição intelectual do ser humano, cuja vigência, como conjunto de teoria e ação, frente ao universo natural passou despercebida até muito recentemente, não só é anterior à gerada pelo Ocidente como também remonta à própria origem da espécie humana e constitui, no conjunto, numa outra forma de aproximação ao mundo da natureza. Chegamos assim a uma conclusão determinante: que entre os seres humanos existem não uma, senão duas maneiras de se aproximar da natureza; que existem, digamos assim, não uma, senão duas "ecologias".

Essa maneira dupla de aproximação intelectual foi registrada por alguns autores desde a sociologia da ciência ou desde a filosofia: Feyerabend (1982) as chamou de "conhecimento abstrato" e "conhecimento histórico", enquanto que para Villoro (1982) se deve diferenciar entre "o conhecer" e "o saber". Sem dúvida foi Claude Lévi-Strauss em seu livro O pensamento selvagem $(1964$, p. 32$)$ quem de maneira taxativa estabeleceu uma distinção nítida entre o que dominou a "ciência neolítica" e a "ciência moderna":

[...] para elaborar as técnicas, muitas vezes prolongadas e complexas, que permitem cultivar sem terra, ou sem água, transformar grãos ou raízes tóxicas em alimentos, ou ainda mais, utilizar essa toxicidade para a caça, o ritual ou a guerra, não nos caiba a menor dúvida de que foi requerida uma atitude mental verdadeiramente científica, uma curiosidade assídua e perpetuamente alerta, um gosto do conhecimento pelo prazer do conhecer, pois uma fração somente das observações e das experiências podiam dar resultados práticos e imediatamente utilizáveis (LÉVI- STRAUSS, 1964, p. 32).
Diante da interrogação de porque o conhecimento científico é tão recente enquanto existiram grandes conquistas da humanidade desde pelo menos dez mil anos, situação que denominou de "paradoxo neolítico", Lévi-Strauss responde:

O paradoxo não admite mais do que uma solução: a de que existem duas maneiras diferentes de pensamento científico, que tanto um como outro são função, não de etapas desiguais do desenvolvimento do espírito humano, mas dos dois níveis estratégicos em que a natureza se deixa atacar pelo conhecimento científico: um deles quase ajustado ao da percepção e o da imaginação e o outro deslocado; como se as relações necessárias, que constituem o objeto de toda a ciência, seja neolítica ou moderna, pudessem ser alcançadas por duas vias diferentes: uma delas muito próxima à intuição sensível e a outra mais afastada (1964, p. 33).

[...] Essa ciência do concreto tinha que estar, por essência, limitada a outros resultados além dos prometidos às ciências exatas naturais, mas não foi menos científica, e seus resultados não foram menos reais. Obtidos dez mil anos antes que os outros seguem sendo o substrato de nossa civilização (1964, p. 35).

Se seguíssemos a proposta de Lévi-Strauss, teríamos que aceitar a existência de pelo menos três principais modalidades de conhecimento ao longo da história humana: uma "ciência paleolítica", anterior ao advento da agricultura e do gado, uma "ciência neolítica", com uma antiguidade de 10.000 anos, e uma "ciência moderna", cuja idade remonta a apenas 300 anos, data na qual se fundaram as primeiras sociedades científicas na Inglaterra e na França (Figura 1).

\section{As “outras ecologias"}

Antes do advento do século vinte, em 1889, J. A. Voelcker, destacado cientista da Royal Agricultural Society da Inglaterra, foi enviado pelo governo de seu país para explorar as vantagens e virtudes da agricultura hindu. Depois de um ano percorrendo os campos agrícolas da Índia, Voelcker publicou um relatório, que apareceu por volta de 1893, no qual ele descreveu com detalhes as destrezas da agricultura campesina. Sua informação foi praticamente 


\section{Conocimiento Humano (perspectiva histórica)}

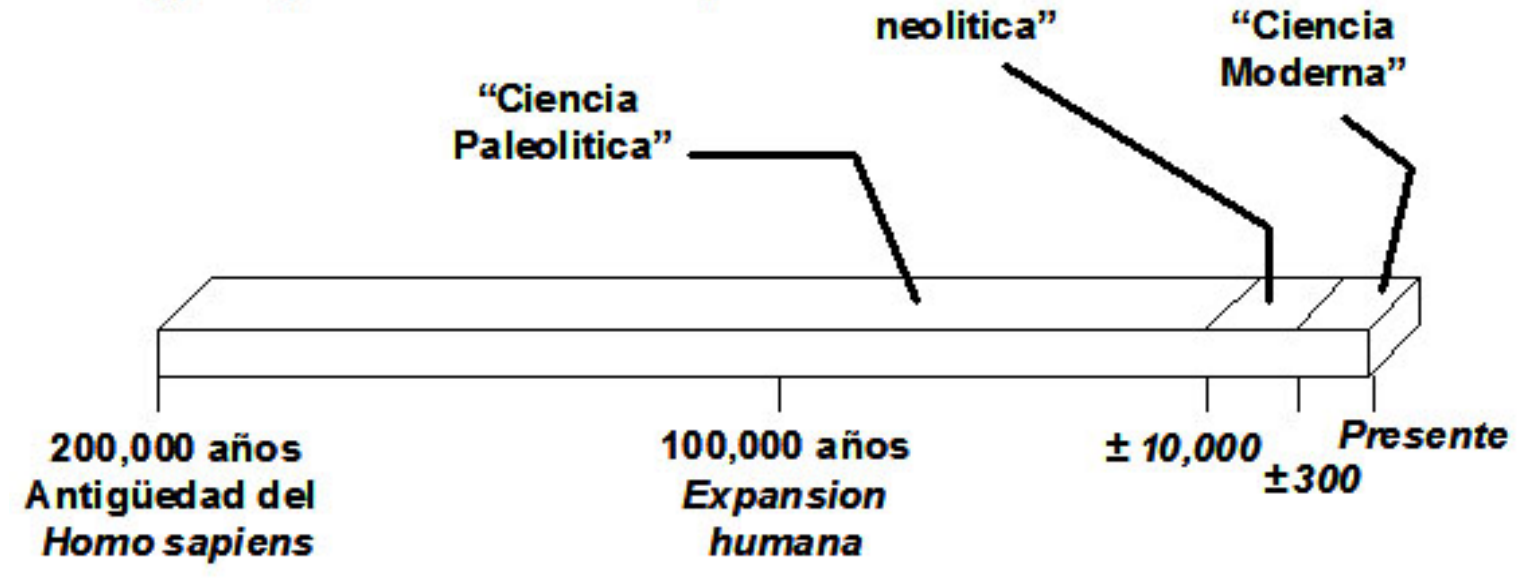

\section{Tiem po}

FIGURA 1 - AS TRÊS PRINCIPAIS MODALIDADES DO CONHECIMENTO HUMANO SOBRE A NATUREZA. INSPIRADO EM LÉVI-STRAUSS (1964).

ignorada pelos especialistas de sua época. Uns anos depois, em 1911, F. H. King, então diretor da Divisão de Solos do Departamento de Agricultura dos Estados Unidos, publicou Farmers of Forty Centuries: permanent agriculture in China, Korea and Japan, uma das poucas obras dedicadas a documentar com detalhes as formas não ocidentais de utilização da natureza.

Testemunha direta e descritor perspicaz, um dos mais profundos conhecedores da problemática agrícola de seu tempo, viu-se profundamente impressionado pela destreza das técnicas de produção asiáticas. Naquela época, os sistemas não industriais descritos permitiam alimentar ao redor de 500 milhões de seres humanos em uma superfície menor do que a de toda a área agrícola dos Estados Unidos e sobre solos utilizados durante cerca de 4.000 anos! De acordo com King, nessa época os campesinos chineses produziam três vezes mais cereais que os agricultores norte-americanos por unidade de superfície e alguma coisa similar acontecia na Coréia e no Japão. As numerosas técnicas e estratégias utilizadas pelos camponeses desses países incluíam um complexo sistema de canais e áreas de irrigação, fertilizantes orgânicos (incluindo restos agrícolas, adubos verdes, dejetos domésticos, estercos, misturas e cinzas) e variedades de cereais bem adaptados às condições dessas regiões.

A essa obra pioneira, resgatada recentemente do esquecimento, seguiu sem dúvida um longo período de várias décadas durante as quais a fascinação pelas novas tecnologias agrícolas derivadas da química e a genética e do uso de combustíveis fósseis sepultou a experiência de manejo da natureza adquirida pela espécie humana em sua modalidade neolítica ou pré-industrial (TOLEDO; BARRERA-BASSOLS, 2008). A conversão de uma agricultura baseada no uso da energia solar (e biológica) até outra onde a energia obtida dos minerais metálicos e não metálicos se torna imprescindível, se tornou sem dúvida um divisor de águas histórico. Essa tendência alcançou sua máxima expressão com a consolidação do modelo de agricultura representado pela chamada "Revolução Verde". Até a década de 1950 todas as baterias da investigação científica sobre o uso dos recursos naturais focaram basicamente a 
busca de variedades genéticas melhoradas, à produção de agroquímicos e o desenho de maquinário agrícola movido por energia fóssil.

A década dos oitenta do século XX foi, sem dúvida, um tempo de retorno às "outras ecologias". Esse foi um movimento motivado pela crescente consciência sobre a crise ecológica do planeta e pela crescente acumulação de evidências empíricas, mostrando a incapacidade dos sistemas produtivos modernos para realizar um uso correto dos recursos naturais. Nas últimas três décadas temos visto o desenvolvimento de inumeráveis projetos e investigações sobre as formas de uso e manejo dos recursos naturais por parte das sociedades tradicionais, o aparecimento de publicações especializadas (Indigenous Knowledge and Development Monitor, Etnoecológica, Journal of Ethnobiology etc.), a criação de núcleos ou sociedades de investigadores e a realização de numerosos congressos nacionais e internacionais focados em ditos temas.

\section{Traços principais do conhecimento tradicional ou local}

A população tradicional ou pré-moderna do mundo é formada por um "núcleo duro" de uns 300-500 milhões de humanos representados pelos chamados povos indígenas que falam umas 7.000 línguas (TOLEDO, 2001), e por um "núcleo fraco" formado por uns 1.300 a 1.600 milhões de camponeses, pescadores, pastores e pequenos produtores familiares (PRETTY, 1995; TOLEDO; BARRERA-BASSOLS, 2008). Tomando-os em conta, é necessário sublinhar que todo produtor rural requer "meios intelectuais", quer dizer, conhecimentos sobre seu entorno, para realizar a apropriação de suas naturezas. Esses conhecimentos têm um valor substancial para clarificar as formas como os produtores tradicionais percebem, concebem e conceituam os recursos, paisagens ou ecossistemas dos quais dependem para subsistir. Mais ainda, no conceito de uma economia de subsistência, esse conhecimento sobre a natureza se converte em um componente decisivo para o esboço e implantação de estratégias de sobrevivência.

A transmissão desse conhecimento se dá por meio da língua e, até onde sabemos, não lança mão da escrita; quer dizer, é um conhecimento ágrafo. A memória é então o recurso mais importante da vida desses povos. Sendo um conhecimento que se transmite no espaço e no tempo pela língua, configura-se e responde a uma lógica diferente: a da oralidade. As sociedades orais não são necessariamente sociedades analfabetas, porque sua oralidade não é falta de escrita, mas sim não necessidade de escrita (MALDONADO, 1992). Para ele, confundir e qualificar a oralidade como uma forma de analfabetismo é um equívoco. Esse corpo de conhecimentos que na realidade constitui a dupla expressão de certa sabedoria (pessoal ou individual e comunitária ou coletiva), é também a síntese histórica e espacial transformada em realidade na mente de um produtor ou de um conjunto de produtores. É uma memória diversificada diante da qual cada membro do grupo social detecta uma parte ou fração do saber total da dita comunidade.

As sociedades tradicionais albergam um repertório de conhecimento ecológico que geralmente é local, coletivo, diacrônico, sincrético, dinâmico e holístico (TOLEDO, 2002). Esses sistemas cognitivos sobre os recursos naturais circundantes são, além disso, transmitidos de geração a geração. O corpus contido em uma só mente tradicional expressa um repertório de conhecimentos que se projetam sobre duas dimensões: o espaço e o tempo. Sobre o eixo espacial, os conhecimentos revelados por um só indivíduo, quer dizer, por um só informante, na realidade são a expressão personalizada de uma bagagem cultural que, dependendo da escala, projeta-se da coletividade à qual dito informante pertence: o núcleo ou unidade familiar, a comunidade rural, o território e, no fim, grupo ou sociedade étnica ou cultural.

No interior da família, o conhecimento se divide e se matiza de acordo com o gênero e idade, pois cada um de seus membros realiza atividades específicas que outorgam ao conhecimento sua própria particularidade. Nos seguintes níveis, a variação do conhecimento coletivamente compartilhado se expressa em função de cada núcleo familiar, cada comunidade específica, cada território e, finalmente, em função da identidade que outorga o fato de pertencer a uma coletividade geralmente diferenciada pela língua.

Na dimensão do tempo (ou histórica), o conhecimento contido em um só informante é a síntese de pelo menos três vertentes: (i) a experiência historicamente acumulada e transmitida por meio de gerações por uma cultura rural determinada; (ii) a experiência socialmente compartilhada pelos membros de uma mesma geração (ou um mesmo tempo generacional); e (iii) a experiência pessoal e particular do próprio produtor e sua família, adquirida pela repetição do ciclo produtivo (anual) paulatinamente enriquecido por 
variações, eventos imprevistos e surpresas diversas. Dita variação temporal resulta do grau de alcance que têm os conhecimentos oralmente transmitidos. O saber tradicional é compartilhado e reproduzido mediante o diálogo direto entre o indivíduo, seus pais e avós (em direção ao passado) e/o entre o indivíduo, seus filhos e netos (em direção ao futuro) com a natureza.

O fenômeno resultante é um processo histórico de acumulação e transmissão de conhecimentos, não isento de experimentação, que toma a forma de uma espiral em várias escalas espaço-temporais: desde a do próprio produtor já que durante cada ciclo produtivo sua experiência se vê paulatinamente incrementada sobre a base do aprendido no ciclo imediatamente anterior, até a da comunidade cultural, já que o conhecimento vai se aperfeiçoando (e adaptando) geração pós-geração, à realidade local de cada presente.

A permanência desse conhecimento tradicional sobre a natureza ao longo do tempo (dezenas, centenas e milhares de anos), pode então ser visualizada como uma sucessão de espirais, não isenta de alterações, crises e turbulências. Esse histórico contínuo revela um formidável mecanismo de memorização, quer dizer, de representação, formação e manutenção de lembranças, que no fundo expressa um certo "código de memória".

A revalidação desse processo se expressa, claro, na praxis, quer dizer, no êxito das práticas que permitem, tanto ao produtor individual como a sua coletividade, sobreviver ao longo do tempo sem destruir ou deteriorar sua fonte original de recursos locais. Isso dá suficientes elementos para reelaborar o termo como "tradicional", o qual tem sido recorrentemente aplicado a esse conhecimento, pois, na realidade, cada produtor e/ou coletividade está lançando mão de um conjunto de experiências que são tão antigas como presentes (existiram e existem), da mesma maneira que são tanto coletivas quanto pessoais. Trata-se mais de uma tradição moderna, ou melhor, de uma síntese entre tradição e modernidade, uma perspectiva que, ao ser olhada de soslaio pelos investigadores, serviu para manter a falsa ideia da inoperância e inviabilidade contemporânea dessas "tradições" e, claro, para a justificação automática de tudo o que se considera como "moderno".

\section{A matriz de conhecimentos tradicionais}

Existe uma abundante literatura sobre os saberes tradicionais, produto de várias décadas de investigação. Não obstante o anterior, fizeram-se poucos esforços para lograr uma sistematização dessa acumulação de estudos, a qual é um reflexo do estilo especializado que predominou na grande maioria dessas investigações - veja-se uma exceção em Ellen (1982). Contrariamente ao especulado, na mente do produtor tradicional existe um detalhado catálogo de conhecimento acerca da estrutura ou dos elementos da natureza, as relações que se estabelecem entre estes, seus processos e dinâmicas e seu potencial utilitário. Dessa forma, no saber local existem conhecimentos detalhados de caráter taxonômico sobre constelações, plantas, animais, fungos, rochas, neves, águas, solos, paisagens e vegetação, ou sobre processos geofísicos, biológicos e ecológicos, tais como movimentos de terras, ciclos climáticos ou hidrológicos, ciclos de vida, períodos de floração, frutificação, germinação, zelo ou nidificação, e fenômenos de recuperação de ecossistemas (sucessão ecológica) ou de manejo da paisagem.

De maneira similar, o conhecimento local não se restringe aos aspectos estruturais da natureza ou que se referem a objetos ou componentes e sua classificação (etnotaxonomias), como também se refere a dimensões dinâmicas (de padrões e processos), relacionais (ligados às relações entre os elementos e os eventos naturais) e utilitárias dos objetos e recursos naturais. Essa primeira classificação se cruza por igual com conhecimentos sobre os fenômenos de caráter astronômico, geofísico, biológico, ecológico e geográfico. A combinação dessas duas dimensões ou eixos serve de marco de referência para localizar, de maneira sistemática, os conhecimentos tradicionais (Quadro 1). Esta, por sua vez, deve ser referida a uma terceira dimensão, a do espaço, pois os conhecimentos operam sempre em diferentes escalas espaço-temporais. Dessa maneira, é possível reconhecer uma escala cultural que abarca teoricamente o "saber total" de certa coletividade, uma escala regional, demarcada pelo território histórico e pela natureza cultivada que o circunda; uma escala comunitária, que se refere ao espaço apropriado por uma comunidade; uma escala doméstica, delimitada pela área de apropriação de um produtor e sua família, e uma escala individual restrita ao espaço do próprio indivíduo. 
QUADRO 1 - MATRIZ DE CONHECIMENTOS TRADICIONAIS. FONTE: TOLEDO; BARRERA-BASSOLS (2008).

\begin{tabular}{|c|c|c|c|c|c|c|}
\cline { 2 - 6 } \multicolumn{1}{c|}{} & Astronómico & \multicolumn{3}{|c|}{ Física } & \multirow{2}{*}{ Biológica } & Ecogeográfica \\
\cline { 3 - 6 } Estructural & $\begin{array}{c}\text { Atmósfera } \\
\text { astros }\end{array}$ & $\begin{array}{c}\text { Litósfera } \\
\text { Tipos de } \\
\text { clima, vien- } \\
\text { tos, nubes }\end{array}$ & $\begin{array}{c}\text { Hnidades de } \\
\text { relieve, rocas }\end{array}$ & $\begin{array}{c}\text { Tipo de } \\
\text { aguas }\end{array}$ & $\begin{array}{c}\text { Plantas, } \\
\text { animales, } \\
\text { hongos, } \\
\text { microbios }\end{array}$ & $\begin{array}{c}\text { Unidades de } \\
\text { vegetación y } \\
\text { paisaje }\end{array}$ \\
\hline Relacional & Varios & Varios & Varios & Varios & Varios & Varios \\
\hline Dinámico & $\begin{array}{c}\text { Movimientos y } \\
\text { ciclos solares, } \\
\text { lunares, } \\
\text { estelares }\end{array}$ & $\begin{array}{c}\text { Movimiento } \\
\text { de vientos y } \\
\text { nubes }\end{array}$ & $\begin{array}{c}\text { Erosión de } \\
\text { suelo y } \\
\text { otros }\end{array}$ & $\begin{array}{c}\text { Movimiento } \\
\text { del } \\
\text { agua }\end{array}$ & $\begin{array}{c}\text { Ciclos de } \\
\text { vida }\end{array}$ & $\begin{array}{c}\text { Sucesión } \\
\text { ecológica }\end{array}$ \\
\hline Utilitario & Varios & Varios & Varios & Varios & Varios & Varios \\
\hline
\end{tabular}

Chega-se então a uma simples matriz sobre os conhecimentos tradicionais. Tanto quanto obedece às necessidades de sistematização do investigador, dita matriz deve, sem dúvida, ser manejada com prudência, pois na mente do produtor cada tipo de conhecimento aparece sempre com referência ao contexto espaço-temporal que opera como cenário dos recursos, e numa certa tensão, isto é, sempre em relação ou em conjugação com o resto.

Da gama de conhecimentos locais, o referido aos solos é o que cobra maior significado desde o ponto de vista agroecológico (BARRERA-BASSOLS; ZINCK, 2003a) Ao longo das duas últimas décadas, o número de estudos etnopedológicos realizados globalmente se incrementou consideravelmente, pondo em evidência um crescente interesse agronômico pelos conhecimentos locais dos solos. Os solos como elementos físicos não somente são de primeira importância por razões agrícolas, como também constituem a base da olaria, a construção de casas e, em algumas ocasiões, adquirem usos medicinais. Além disso, o conhecimento e uso dos solos servem, como veremos, como um critério nodal na tomada de decisões sobre as formas de manejar as paisagens que formam o entorno local.

Existe, ademais, um elaborado sistema vernáculo de nomenclatura e classificação dos solos, e contrariamente ao previamente pensado por alguns autores, a percepção indígena dos solos pode ser de caráter tridimensional, já que existe também conhecimento sobre os horizontes ou camadas do solo (BARRERA-BASSOLS, 1988; 2008). Uma revisão exaustiva da literatura registrou 432 estudos etnopedológicos em 61 países da África, América e Ásia. Essa informação se refere a 217 grupos étnicos, que incluem uma grande variedade de comunidades indígenas e camponesas que vivem em três das zonas agroecológicas mais frágeis do mundo: o trópico úmido, o trópico seco e as zonas montanhosas frias (BARRERA-BASSOLS; ZINCK, 1998, 2000, 2003b).

Existem quatro critérios fundamentais utilizados por povos com diferentes tradições culturais para a classificação dos solos: a cor $(100 \%)$ e a textura $(98 \%)$; a consistência (56\%) e umidade do solo (55\%); a matéria orgânica, pedregosidade, topografia, uso da terra e drenagem (entre 34 e $48 \%$ ); e a fertilidade, produtividade, estrutura, profundidade e temperatura do solo (entre 2 e $26 \%$ ). Além disso, os atributos usados mais frequentemente para classificar o solo são os morfológicos, entre os quais a cor e a textura são os mais representativos.

\section{O corpus tradicional, o conjunto de conhecimentos e seu significado prático}

Como se articulam os diferentes tipos de conhecimento no corpus tradicional e com que objeto? Esta pergunta relaciona a dimensão cognitiva com as práticas. A chave se encontra na distinção de unidades no espaço. A literatura abunda em exemplos sobre os termos utilizados pelos povos tradicionais para distinguir e nomear grandes unidades da paisagem com base no relevo ou nas grandes estruturas geomorfológicas. Praticamente toda cultura possui termos para designar os principais acidentes de seu espaço terrestre (planícies, vales, declives, montanhas, picos) ou aquático (DUVALL, 2008). Neste contexto, resulta interessante a análise dos topônimos (nomes atribuídos a lugares específicos) que normalmente denotam alguma característica do lugar que valorizam. 
O conhecimento dirigido a distinguir unidades ambientais no espaço imprime sentido em termos práticos porque geralmente estas operam como unidades de manejo nas estratégias de apropriação dos recursos naturais. Se a esta dimensão denominamos como ecogeográfica é porque encontra sua equivalente nas unidades de manejo propostas pela ecogeografia (TRICART; KILLIAN, 1982) ou desde a ecologia da paisagem (ZONNEVELD, 1988). Estas unidades desempenham um papel central no conjunto de estratégias particulares e gerais que os produtores operam durante o processo de apropriação da natureza.
Só até recentemente esta dimensão perceptual começou a ser reconhecida e analisada como tal pelos pesquisadores. Em um trabalho sobre o assunto, Berkes e colaboradores discutiram a possibilidade de distinguir um conceito equivalente ao de ecossistema no corpus indígena ou tradicional.

A investigação acumulada durante a última década, mostra que a habilidade de discriminar unidades no universo natural está relacionada com o tipo de habitat e, especialmente, com as atividades dos produtores tradicionais. Com efeito, os critérios utilizados pela mente tradicional

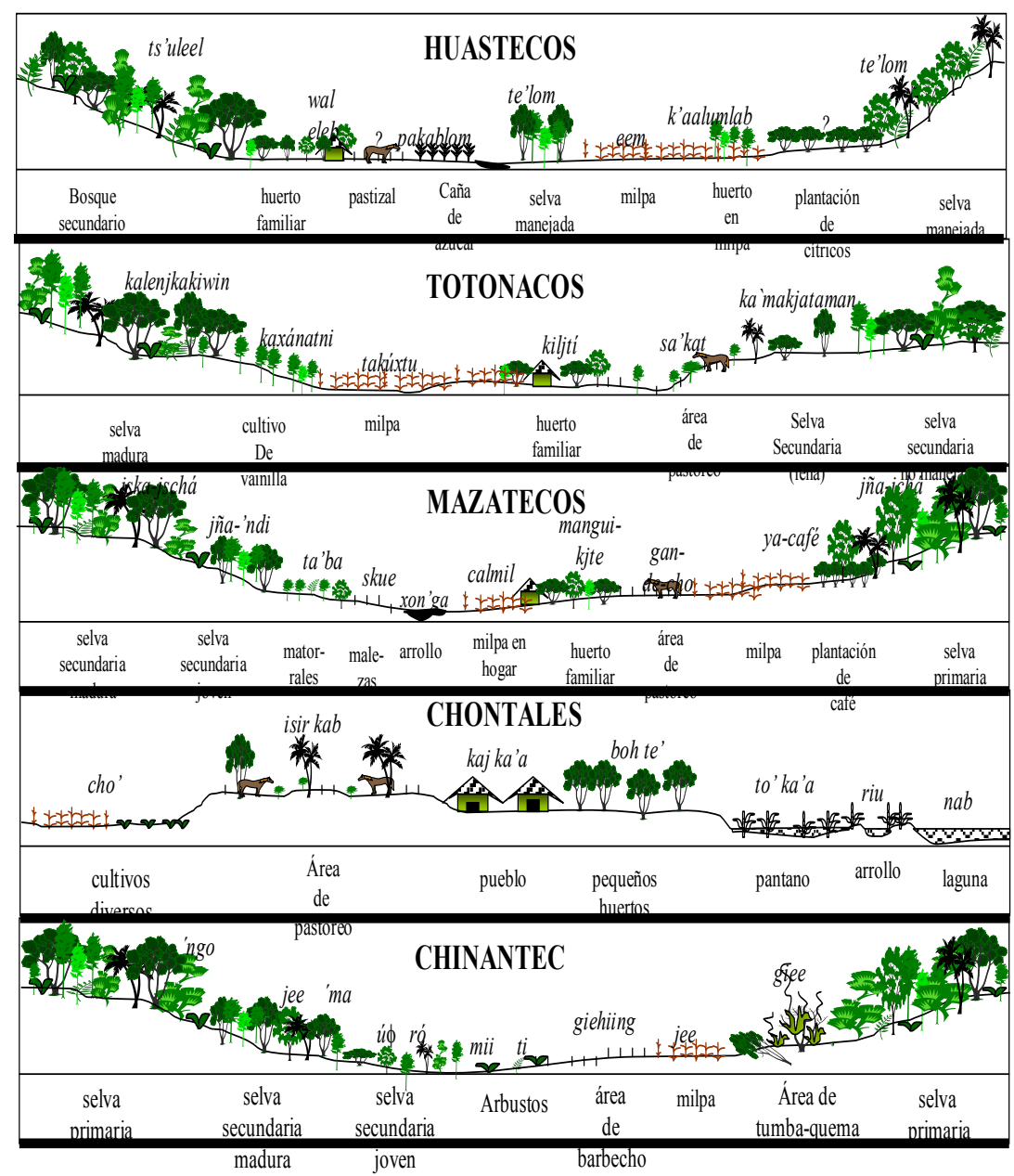

FIGURA 2 - PRINCIPAIS UNIDADES DE PAISAGEM DISTINGUIDAS POR CINCO GRUPOS INDÍGENAS TROPICAIS ÚMIDAS DO MÉXICO. FONTE: TOLEDO ET AL., 2003 
diferem quando se trata de distinguir unidades nas massas florestais, as quais adquirem valor para a prática de caça e colheita, quando os espaços são convertidos à agricultura ou aos rebanhos ou quando se trata de classificar unidades em corpos de água (rios, lagoas, lagos e mares), de utilidade para as atividades pesqueiras. Sem dúvida, apesar dessa variação, tudo indica que a diferença de unidades nas paisagens florestais, agropecuárias ou pesqueiras, é resultado de uma operação comum que faz parte dos procedimentos normais de toda estratégia tradicional de uso dos recursos.

Em sua versão mais óbvia, os produtores tradicionais ligados estreitamente a bosques ou selvas, diferenciam unidades ecogeográficas baseados nos principais conjuntos de vegetação ou suas variantes (associações vegetais), como foi mostrado para diferentes regiões do mundo (veja-se o caso do México na Figura 2). No trópico úmido, por exemplo, a terminologia espanhola de camponeses Mestiços inclui até 35 categorias ou taxa, segundo foi mostrado por um botânico na área da Guatemala e Belize (BARTLETT, 1936). Na região Amazônica, os Caiapó empregam 16 termos para categorizar as diferentes situações da vegetação de dois principais biotopos: selvas e savanas (HECHT; POSEY, 1988).

A complexidade das classificações indígenas sobre as unidades de paisagens florestais adquire sua máxima expressão na que se considera a região biologicamente mais rica do mundo, isto é, as selvas da parte ocidental da Amazônia na fronteira entre Peru e Brasil. Os estudos realizados por Fleco e Harder (2000) entre os Matses da bacia do rio Gálvez, Peru, um povo de só 150 membros, e por Shepard e colaboradores (2001) com os Machiguenga, também da Amazônia Peruana, oferecem uma descrição detalhada dos complexos sistemas indígenas de classificação de "habitats" selváticos. No caso dos Matses, se distinguem 104 tipos de selvas primárias e 74 tipos de selvas secundárias em um raio de $800 \mathrm{~km}^{2}$. Por seu lado, os Machiguenga discriminam um total de 97 unidades selváticas: 76 delas definidas por critérios bióticos e 21 por fatores físicos ou de outro tipo. Em ambos os casos, os critérios utilizados foram tipos ou associações de vegetação, hidrologia, topografia, tipos de solos, regimes estacionais (como as oscilações hídricas resultado dos ciclos de chuva e seca, incêndios e quedas de árvores), indicadores ecológicos (como a idade da selva em restauração), de fauna, de flores e outros fatores. Em ambos os casos, esta finíssima classificação de habitats selváticos serve aos produtores para traçar estratégias de caça e colheita, assim como para o estabelecimento de zonas hortenses. A complexidade dessas discriminações indígenas deixa muito para trás as classificações elaboradas pelos principais estudiosos da ecologia florestal amazônica (SHEPARD et al., 2001).

Esse conhecimento sobre as descontinuidades da vegetação não parece, sem dúvida, ter maior sentido senão como parte ou fração de um processo através do qual a mente do produtor sintetiza ou combina seus conhecimentos das unidades de vegetação com os do solo e acidentes topográficos ou do relevo e outros fatores. O resultado desta síntese é o reconhecimento de unidades ecogeográficas (agro-habitats, micro-habitats, "facets écologiques" ou "resource-units"), cada uma delas com um particular potencial produtivo, a partir das quais o produtor escolhe e traça suas estratégias. Este fenômeno foi ilustrado pelo estudo de diversos grupos culturais e em vários casos alcança um alto grau de complexidade e perfeição. A Figura 3 mostra o caso dos Maias de Yucatan, México.

Dessa maneira, o produtor tradicional realiza as mesmas operações que os chamados "sistemas de avaliação de terras". Em um caso utilizando "mapas mentais" e no outro uma cartografia sofisticada: os Sistemas de Informação Geográfica (SIGs). Com ele se consegue distinguir as diferentes ofertas ambientais de cada unidade de paisagem do entorno local. Isto resulta crucial para o estabelecimento de sistemas produtivos ecologicamente adequados e, de certa forma, explica a permanência e vigência de muitos sistemas agrícolas, pecuários, pastoris, caça e colheita e agroflorestais de caráter tradicional, alguns deles com idades de centenas e inclusive de milhares de anos.

\section{A etnoecologia: o estudo da "sabedoria" tradicional}

Nas últimas seções oferecemos uma síntese apertada dos avanços logrados pela ciência acerca do conhecimento tradicional ou local sobre a natureza. Sem dúvida, o enfoque adotado na maioria dos estudos é limitado, porque aborda o fenômeno cognitivo fora do contexto cultural desses povos, e porque parte de um pressuposto falso: que as formas de conhecimento pré-industriais existem, como no caso da ciência, separados das outras dimensões da vida cotidiana. As reflexões teóricas e metodológicas e as aprendizagens empíricas realizadas pelos autores durante quase três déca- 


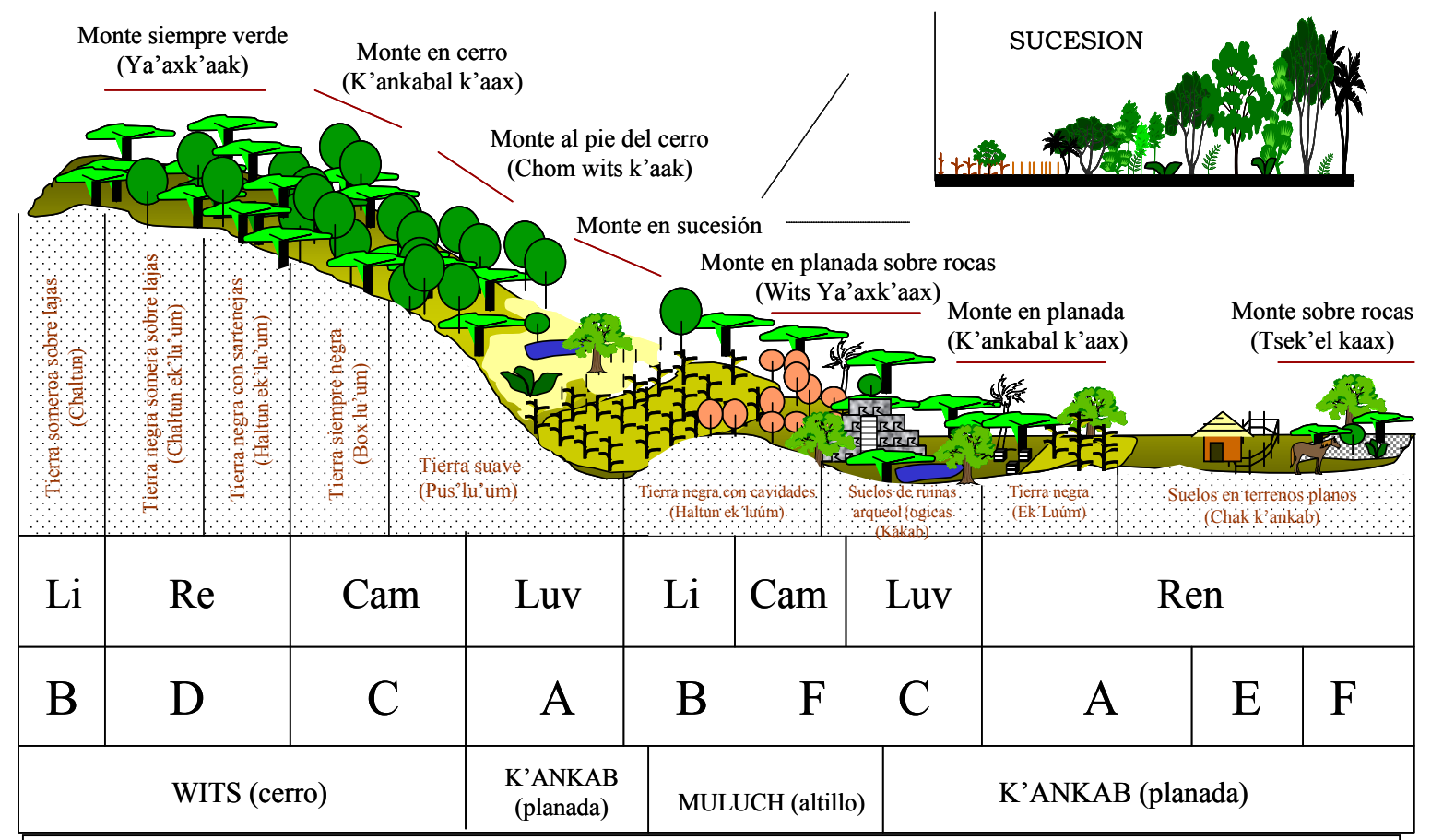

SUELOS: Li, litosol; Re, regosol; Cam, cambisol; Luv, luvisol; Ren, rendzinas

AGROHABITATS: A, suelos negros en relieve plano muy fértiles; B, suelos negros en cerros; $\mathrm{C}$, suelos suaves en cerros; D, suelos negros en cerros; E, suelos rojos en relieve plano; F, suelos rojos y negros sobre rocas en planos.

FIGURA 3 - UNIDADES DE MANEJO (AGRO-HABITATS) RECONHECIDAS E NOMEADAS PELOS MAIAS YUCATECOS DA COMUNIDADE DE XOCÉN, EM YUCATAN, MÉXICO, COM BASE NA VEGETAÇÃO, TOPOGRAFIA E SOLOS. CADA UNIDADE DE MANEJO É ASSINALADA PELAS LETRAS EM MAIÚSCULA. FONTE: SANABRIA (1986).

das (TOLEDO, 1992; 2001; 2002; BARRERA-BASSOLS, 2000, 2008; TOLEDO; BARRERA BASSOLS, 2008) promoveram o surgimento de um novo enfoque, isto é, a etnoecologia, baseado na pressa de que os conhecimentos tradicionais na realidade fazem parte de uma sabedoria tradicional, que é o verdadeiro núcleo intelectual e prático por meio do qual essas sociedades se apropriam da natureza, mantêm-se e reproduzem-se ao longo da história.

Para compreender de maneira adequada os saberes tradicionais, é então necessário entender a natureza da sabedoria local, que se baseia em uma complexa inter-relação entre as crenças, os conhecimentos e as práticas. A natureza se concebe, valoriza e representa sob seus domínios visíveis e invisíveis. As sabedorias tradicionais baseiam-se nas experiências que se têm sobre o mundo, seus feitos e significados, e sua valorização de acordo com o contexto natural e cultural onde se desdobram. Os saberes (ambientais) são então uma parte ou fração essencial da sabedoria local.

Hoje, parece claro que os saberes locais, para ser corretamente compreendidos, devem ser analisados em suas relações tanto com as atividades práticas como com o sistema de crenças do grupo cultural ao que pertencem (BERKES, 1999). Do contrário, cai-se no erro de realizar uma compreensão descontextualizada dos ditos saberes, reproduzindo uma tendência na investigação convencional: a de separar o objeto de estudo de suas relações com o todo (holon) dentro do qual está imerso.

A conclusão obrigatória é de que o conhecimento tradicional deve ser contemplado em sua íntima ligação com seu sistema de crenças. Isso permite compreender muitas das voltas e matizes que toma o conhecimento objetivo na mente do produtor rural, além de estabelecer seus próprios limites práticos. Exemplos do anterior são muitos sistemas folk ou tradicionais de classificação biológica 
que aparecem amalgamados com seu sistema de crenças, ou a sobreposição que existe entre os calendários rituais, agrícolas e astronômicos de muitas culturas, ou, enfim, o reconhecimento de unidades no espaço intimamente ligadas a certa sofisticação perceptual ou a um determinado sistema de representações simbólicas e práticas.

\section{A etnoecologia como análise do complexo "kosmos-corpus-praxis"}

O surgimento e desenvolvimento da etnoecologia, com seu enfoque holístico e multidisciplinar, permitiram o estudo do complexo integrado pelo sistema de crenças (kosmos), o conjunto de conhecimentos (corpus) e de práticas produtivas (praxis), o que torna possível compreender cabalmente as relações que se estabelecem entre a interpretação e leitura e o uso ou manejo da natureza e seus processos (TOLEDO, 1991, 2002; BARRERA-BASSOLS; TOLEDO, 2005; Figura 4).

Desta maneira, a etnoecologia se propõe a estudar a integração do complexo kosmos-corpus-praxis (k-c-p) den- tro dos processos de teorização, representação e produção nas diversas escalas espaço-temporais. Os etnoecólogos precisam então interpretar os modelos do mundo natural que possuem os produtores, famílias e comunidades com culturas tradicionais, com o fim de compreender em toda sua complexidade as sabedorias locais. Em paralelo, os etnoecólogos também geram um modelo científico "externo" sobre o mencionado contexto local. O enfoque etnoecológico busca então integrar, comparar e validar ambos os modelos para criar diretrizes que apontem a implementação de propostas de desenvolvimento local endógeno ou sustentável com a plena participação dos atores locais. Assim, seu enfoque busca encontrar possíveis sinergias entre ambas as maneiras de valorizar o mundo e o consequente aproveitamento dos recursos naturais.

\section{A dinamização do complexo " $k-c-p$ ": o cenário giratório}

Pelo estabelecido anteriormente, os atores tradicionais encenam três atos distintos, mas articulados e inclu-

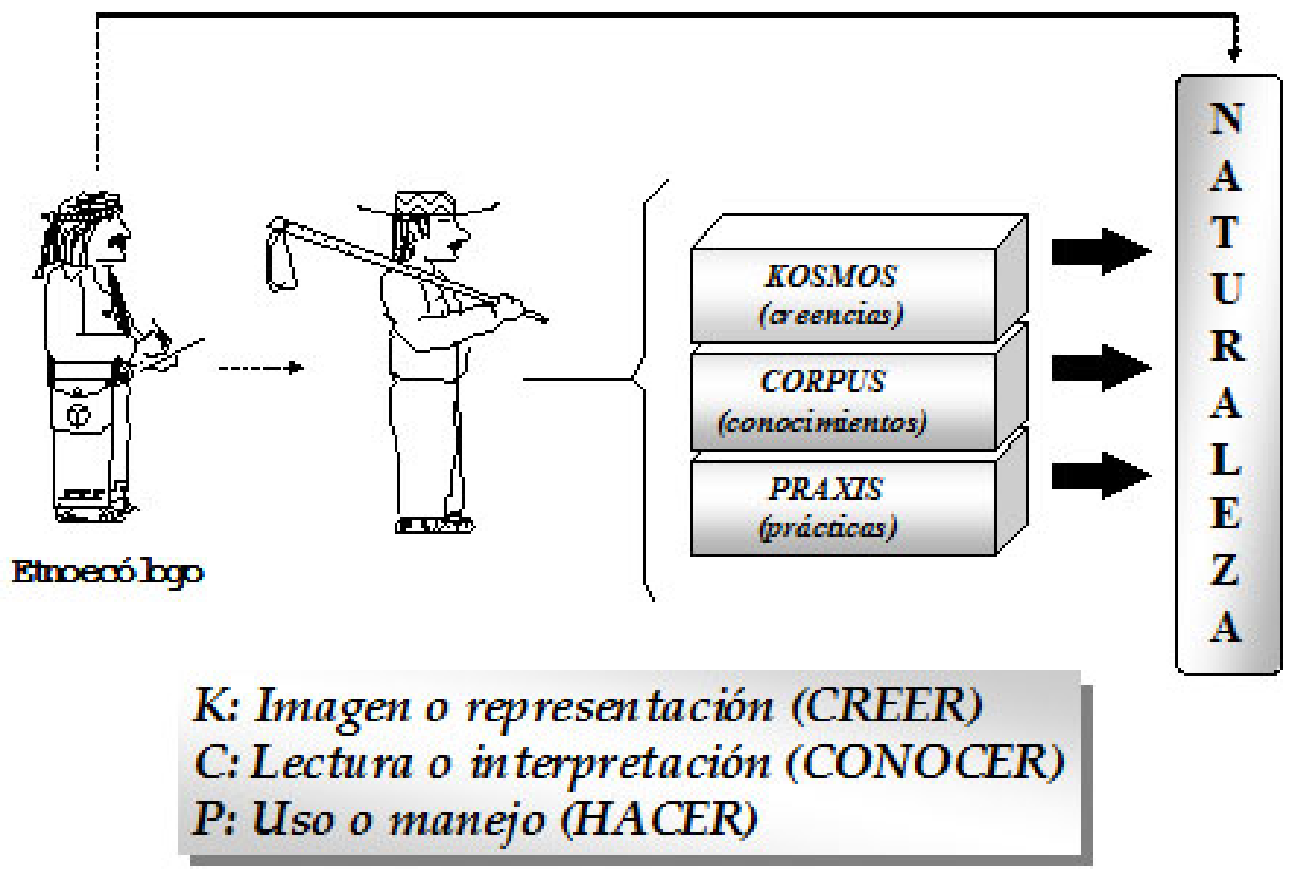

FIGURA 4 - A ETNOECOLOGIA COMO ESTUDO DA REPRESENTAÇÃO, INTERPRETAÇÃO E MANEJO DA NATUREZA. 
sive sincronizados, diante de seu cenário produtivo: duas interpretações e uma atuação. Desde a perspectiva de seu repertório ou sistema de crenças, os atores constroem uma imagem ou representação do cenário produtivo (simbólico e material): a "sobrenatureza". Por outro lado, os atores constroem, em paralelo, uma interpretação desse mesmo cenário mediante uma leitura baseada na observação de objetos, feitos, padrões e processos, quer dizer, através do repertório de conhecimentos acumulados. Finalmente, os atores decidem e constroem uma atuação baseada na dupla representação/interpretação, isto é, põem em operação um conjunto de ações em relação a seu cenário mediante a tomada de decisões baseadas em um repertório de práticas produtivas.

Essa tríade de atos representa, em essência, o processo geral de apropriação (intelectual e material) da natureza. Sem dúvida, o anterior expressa somente a dimensão atemporal do dito complexo. Desde este ponto de vista se trata de uma interpretação estática. Este complexo fica dinamizado (cinemática) uma vez que essa tríplice relação entre o ator e seu cenário produtivo é jogada na ímpia dimensão do tempo: a jornada ou sucessão noite/dia, o ciclo anual (ano solar), o ciclo generacional e os transcursos históricos de caráter transgeneracional.

Dada à forma circular que é o traço como se expressa o tempo, quer dizer, a concatenação dos ritmos humanos com os ciclos naturais, os atores ficam situados no próprio centro de um espaço que se desloca de maneira circular; isto é, terminam se situando no centro de um cenário giratório (Figura 5). Os atores produtivos são, assim, o eixo desde onde se dá a engrenagem entre a dimensão do kosmos, a do corpus, e a da praxis. Por exemplo, a concatenação entre o calendário ritual (festas e celebrações), o calendário cognitivo (que testemunha, por exemplo, mudanças na floração, os ciclos de vida dos animais, os movimentos da Lua, as estrelas ou as constelações, as épocas de estabelecimento do ninho ou desova, etc.), e o calendário agrícola ou pesqueiro (e do resto das atividades produtivas).

Os atores, quer dizer, os indivíduos, as famílias, as comunidades, os territórios étnicos e, enfim, os povos ou culturas que expressam em conjunto uma dimensão espacial, vivem então o jogo da sobrevivência através da dinamização do complexo $k-c-p$ em processos circulares, onde cada um dos quais, dependendo da dimensão temporal, opera como
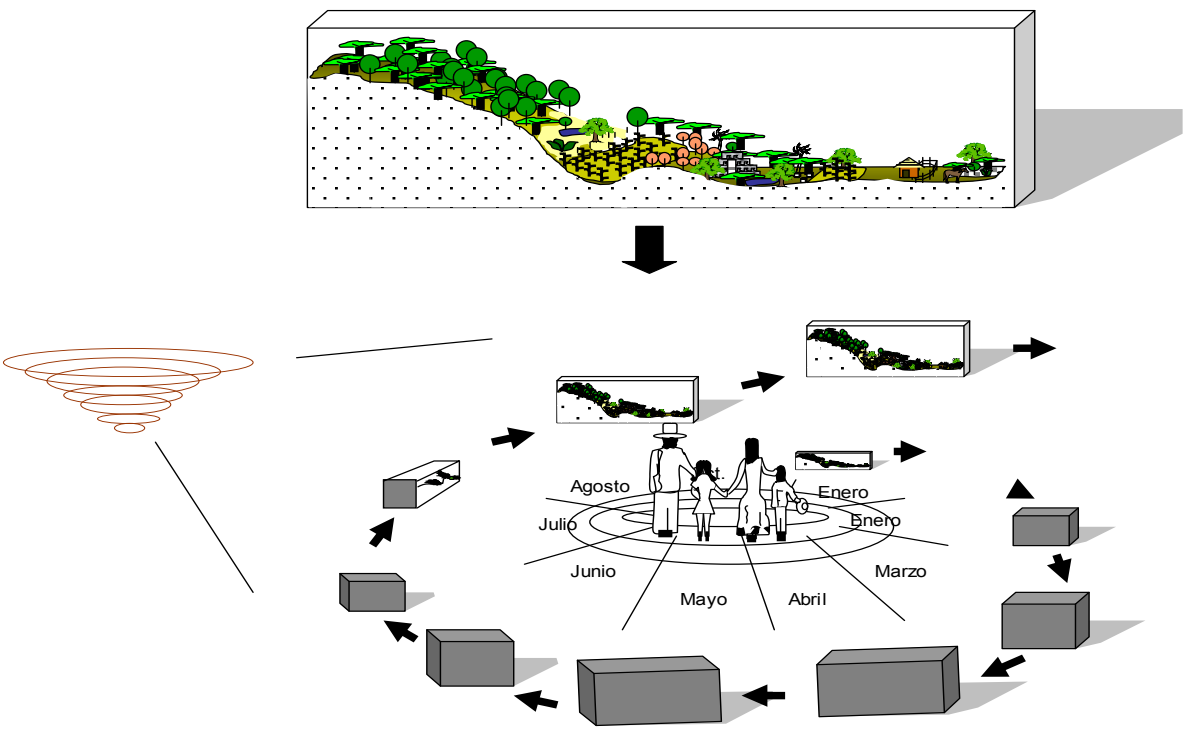

FIGURA 5 - A FAMÍLIA TRADICIONAL VAI DINAMIZANDO SEU COMPLEXO $k$ - $c-p$, POR MEIO DO CICLO ANUAL, O CENÁRIO GIRATÓRIO, QUE, CONFORME PASSAM OS ANOS, DÁ LUGAR A UM CICLO DE CICLOS. 
uma engrenagem dentro de um mecanismo de relojoaria de caráter inclusivo. Assim, a rotação entre a noite e o dia, que aparece para o ator como um processo dual aberto/fechado ou de ação/descanso, faz parte da translação anual, do ano solar. Da mesma forma, o ciclo anual é rotacional dentro do processo de transferência que representa a vida produtiva de um ator. E, enfim, os ciclos de vida produtiva de cada ator fazem parte, por sua vez, dos ciclos mais vastos pelos quais uma cultura imprime por meio de sua história, uma particular maneira de se apropriar da natureza contida em certo cenário regional (o território étnico).

O cenário giratório possui, então, uma inércia circular, tanto quanto é duplamente cíclico (ciclo diário e ciclo anual), mas também contém uma história particular, que é imperceptível para o produtor de primeira mão, tanto quanto se estende por lapsos que excedem a duração do próprio produtor. Dado o anterior, estes "ciclos de ciclos", na realidade, são processos em espiral, na medida em que a acumulação de experiência, memorizada pelas mentes individuais e coletivas de certa cultura, são transmitidas através do tempo como círculos cada vez mais amplos, dando lugar a um processo de aperfeiçoamento que pode ser gradual ou súbito (como saltos) e que, visto hoje em dia, explica a impressionante acumulação de experiência sedimentada em muitas culturas locais.

A capacidade de memorizar, quer dizer, de recordar eventos do passado com o objetivo de tomar decisões no presente, torna-se então um elemento fundamental, não só na acumulação de experiências de um só ator produtivo, e que converte o que pareciam ciclos tediosamente repetitivos em movimentos espirais e ascendentes, assim como em sua socialização com outros indivíduos da mesma geração (memória coletiva ou compartilhada) e, o que é ainda mais importante, com indivíduos de outras gerações.

Cada indivíduo que se enfrenta, dotado de seu complexo $k-c-p$, ao cenário que gira, vai (moldando) aperfeiçoando sua experiência como resultado de três fontes de informação: "o que lhe disseram" (experiência historicamente acumulada), "o que lhe dizem" (experiência socialmente compartilhada), e "o que observa por si mesmo" (experiência individual). Cada indivíduo, então, transmite às novas gerações uma experiência enriquecida e cada vez mais refinada, adaptada a novas circunstâncias. A repetição (adaptada) no tempo desse mecanismo, se não se vê interrompida ou alterada, constitui um processo inegável de aperfeiçoamento. Isso outorga à experiência local o caráter diacrônico e sincrético, assinalado por vários autores (Figura 6).

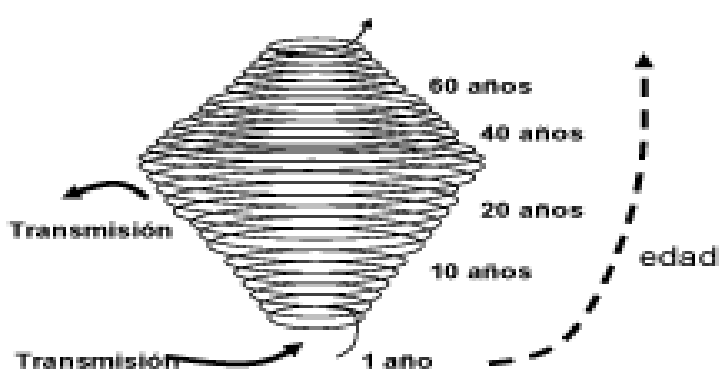

FIGURA 6 - A ACUMULAÇÃO DO CONHECIMENTO, OU DA EXPERIÊNCIA, ADQUIRIDOS POR UM INDIVÍDUO POR MEIO DE CADA CICLO ANUAL, TOMA A FORMA DE ESPIRAL. VER TEXTO.

A unidade familiar vive então imersa nessa matriz espaço-temporal durante seu contato direto e permanente com as forças, os elementos e os ciclos da natureza. E esses conceitos básicos de espaço e de tempo que aparecem intimamente atados à apropriação do universo natural, e que lhes permite manter funcionando o metabolismo entre sua sociedade e sua natureza (versão pré-industrial da "sustentabilidade"), são também o "eixo cósmico" (STEGER, 1991) que dá sentido a sua existência e identidade cultural.

\section{Implicações epistemológicas, culturais e políticas da etnoecologia}

Hoje, o uso dos recursos naturais do planeta se vê cada vez mais confrontado ao dilema entre agroindustrialidade ou agroecologia. No caso de boa parte dos países localizados nas regiões intertropicais (Brasil, Indonésia, Índia, México, Filipinas, Camerún, Nigéria) e/ou onde a população tradicional (indígenas, camponeses minifundiários, pescadores) domina nas áreas rurais (China, Bolívia, Peru, Equador, Guatemala, Egito), o estudo das sabedorias tradicionais é e será uma atividade chave na elaboração de novos modelos agroecológicos. Sem dúvida, esses estudos têm também outras implicações além das produtivas ou técnicas.

O avanço do conhecimento científico se comprova, sobretudo, porque permitiu o advento da crítica e da autocrítica (MORIN, 2002). Nesse contexto, constituiu um 
logro que a ciência tenha aceitado a existência de outras formas de conhecimento, diferentes e prévias, com as quais é preciso dialogar. Desta forma, supera-se o caráter elitista e dominante da ciência moderna, já assinalado, por alguns autores. Pelo anterior, a etnoecologia não somente promove o diálogo de saberes, como a investigação participativa e suas contribuições coadjuvam com a revalorização das culturas indígenas e dos povos camponeses geralmente ignorados, explorados e marginalizados.

Pelo anterior, a etnoecologia não é somente uma abordagem interdisciplinar ou holística, assim como desafia os paradigmas da ciência convencional e é parte do que se

\section{Referências}

BARRERA-BASSOLS, N. Symbolism, knowledge and management of soil and land resources among indigenous communities. Ethnopedology at global, regional and local scales. ITC Dissertation Series 102, 2 vols. ITC, The Netherlands, 2008.

; TOLEDO, V. Ethnoecology of the Yucatec Maya: symbolism, knowledge and management of natural resources. Journal of Latin American Geography (JLAG), v. 4, n. 1, p. 9-41, 2005.

; ZINCK, J. A. Ethnopedology in a worldwide perspective: an annotated bibliography. ITC Publications. Vol. 77. Enschede, The Netherlands, 2000.

."Land moves and behaves": Indigenous discourse on sustainable land management in Pichátaro, Pátzcuaro Basin, México. Geografiska Annaler, v. 85, n. 3-4, p. 266-276, 2003 a.

. Ethnopedology: a worldwide view of the soil knowledge of local people. Geoderma, v. 111, n. 3-4, p. 171-195, $2003 b$.

BARLETT, H. A method of procedure for field work in tropical American phytogeography based upon a botanical reconnaissance in parts of British Honduras and the Peten forest of Guatemala. In: Botany of the Maya area. Carnegie Inst. Washington Misc. Paper, v. 1, p. 3-25, 1936.

BERKES, F. Sacred ecology: traditional ecological knowledge and resource management. Taylor and Francis. Philadelphia, USA, 1999.

; KISLALIOGLU, M.; FOLKE, C.; GADGIL, M. Exploring the basic ecological unit: Ecosystem-like concepts in traditional societies, Ecosystems, v. 1, p. 409-415, 1998. conhece como uma "ciência pós-normal" (FUNTOWICZ; RAVETZ, 1998). A etnoecologia também contribui à crítica do mundo moderno, ao mostrar que existe uma memória biocultural representada pelas muitas sabedorias locais, com antiguidades de centenas e milhares de anos, as quais foram avassaladas pelos modelos de caráter agroindustrial (TOLEDO; BARRERA-BASSOLS, 2008). Isso vem explicar desde uma perspectiva ligada à cultura e ao conhecimento, a aguda crise do mundo contemporâneo. Em suma, a etnoecologia tem a singular tarefa de decifrar a "memória da espécie" e de reivindicar e revalorizar, de passagem, aqueles que a representam e a mantêm viva.

BERLIN, E. A.; BERLIN, B. Medicinal ethnobiology of the highland Maya of Chiapas, Mexico. Princeton University Press, Princeton, New Jersey, 1996.

DUVALL, S. Ch. Classifying physical geographic features: the case of Maninka farmers in southwestern Mali. Geografiska Annaler, Series B, v. 90, n. 4, p. 327-348, 2008.

ELLEN, R. F. Environment, Subsistence and System: the ecology of small-scale social formations. Cambridge University Press, UK, 1982.

FEYERABEND, P. La ciencia en una sociedad libre. Siglo XXI. México D.F., 1982.

FLECK, D. W.; HARDER, J. D. Matses Indian rainforest habitat classification and mammalian diversity in Amazonian Peru. Journal of Ethnobiology, v. 20, p. 1-36, 2000.

FUNTOWICZ, S.; RAVETZ, F. Science for the post-normal age. Futures, v. 25, n. 7, p. 735-755, 1993.

HECHT, S. B.; POSEY, D. A. Preliminary results on soil management techniques of the Kayapo Indians. In: Resources management in Amazonia: indigenous and folk strategies. POSEY, D. A.; BALEE, W. (Eds.) Advances in Economic Botany, v. 7, p. 174-188, 1989.

LÉVI-STRAUSS, C. El pensamiento salvaje. Fondo de Cultura Económica, 1964.

MAFFI, L. (Ed.) On biocultural diversity: linking language, knowledge and the environment. Smithsonian Institution Press, 2001.

MALDONADO, A. B. La historia oral en sociedades orales. Opciones, v. 13, p. 40-45, 1992. 
MORIN, E. Introducción al Pensamiento Complejo. Editorial Gedisa, Barcelona, 2002.

PRETTY, J. N. Regenerating Agriculture: polices and practice for sustainability and self-reliance. Earthscan. London, 1995.

SANABRIA, O. L. El uso y manejo forestal en la comunidad de Xul, en el sur de Yucatán. Etnoflora Yucatanense, v. 2. INIREB. México, 1986.

SHEPARD Jr., G. H.; YU Jr., D. W.; LIZARRALDE, M.; ITALIANO, M. "Rain forest habitat classification among the Matsigenka of the Peruvian Amazon." Journal of Ethnobiology, v. 21, n. 1, p. 1-38, 2001 .

STEGER, H. (Ed.). La concepción de tiempo y espacio en el mundo andino. Vervuert, Frankfurt, 1991.

TOLEDO, V. M. What is ethnoecology?: origins, scope and implications of a rising discipline, Etnoecológica, v. 1, p. 5-21, 1992.

. Indigenous peoples and biodiversity. In: LEVIN, S. et al. (Eds.) Encyclopedia of Biodiversity. Academic Press, 2001.
Ethnoecology: a conceptual framework for the study of indigenous knowledge of nature. In: STEPP, J. R. et al. (Eds.) Ethnobiology and Biocultural Diversity. International Society of Ethnobiology, Georgia, USA, p. 511-522, 2002.

; BARRERA-BASSOLS, N. La Memoria Biocultural: la importancia ecológica de las sabidurías tradicionales. Icaria editorial. Barcelona, España, 2008.

; ORTIZ, B.; CORTÉS, L.; MOGUEL, P.; ORDÓÑES, M. J. The multiple use of tropical forests by indigenous peoples in México: a case of adaptive management. Conservation Ecology, v. 7, n. 3, p. 9, 2003. (Disponível em: http://www. consecol.org/vol7/iss3/art9)

TRICART, J.; KILIAN, J. La eco-geografia y la ordenación del medio natural. Editorial Anagrama, Barcelona, 1982.

VILLORO, L. Creer, Saber, Conocer. Siglo XXI Editores, México, 1982.

ZONNEVELD, I. S. Land ecology: an introduction to landscape ecology as a base for land evaluation, land management and conservation. SPB Academic Publishing, Amsterdam, 1995.

Recebido em maio de 2009.

Aceito em agosto de 2009 Publicado em dezembro de 2009. 